\title{
In situ reconstruction with bovine pericardial tubular graft for aortic graft infection
}

\author{
Reconstrução in situ de enxerto de pericárdio devido à infecção de enxerto aórtico
}

Eduardo DULBECCO ${ }^{1}$, Mariano CAMPORROTONDO², Gustavo BLANCO ${ }^{3}$, Diego HABERMAN ${ }^{4}$

RBCCV 44205-1182

\begin{abstract}
Prosthetic graft infection is a serious complication of abdominal aorta surgery. Its removal is always indicated because it prevents potential significant complications, but reconstruction is a technical challenge. The authors present a case of an in situ reconstruction with corrugated bovine pericardial tubular graft.
\end{abstract}

Descriptors: Vascular surgical procedures. Infection. Aortic aneurysm, abdominal. Pericardium.

\section{INTRODUCTION}

Infrarenal aortic graft infection continues to be one of the most challenging problems in modern vascular surgery. Infection associated with bioprosthetic material can occur in up to $3 \%$ of implanted materials [1].

Successful treatment necessitates the complete excision of the infrarenal aortic graft infection with the maintenance of adequate lower extremity arterial inflow. Patient survival, freedom from recurrent infection, patency of the revascularization, and avoidance of major amputation are important outcome goals used to measure the success of surgical treatment.

Glutaraldehyde-treated bovine pericardial grafts have been used in cardiovascular surgery for aorta replacement.

1. Staff Surgeon of the Division of Cardiac and Vascular Surgery Department of Cardiovascular Surgery.

2. Chief Resident of the Division of Cardiac and Vascular Surgery Department of Cardiovascular Surgery.

3. Resident of the Division of Cardiac and Vascular Surgery Department of Cardiovascular Surgery.

4. Staff Member of the Division of Cardiovascular Imaging Department of Radiology.

Work performed at Favaloro Foundation University Hospital, Buenos Aires, Argentina.

\section{Resumo}

A infeç̧ão de um enxerto é uma complicação séria em cirurgia de aorta abdominal. A remoção deste enxerto é uma indicação obrigatória devido às potenciais e graves complicações. Entretanto, sua reconstrução é uma técnica complexa e, ao mesmo tempo, desafiadora. Os autores apresentam um caso de reconstrução in situ utilizando um enxerto tubular de pericárdio bovino corrugado.

Descritores: Procedimentos cirúrgicos vasculares. Infecção. Aneurisma da aorta abdominal. Pericárdio.

Long term follow-up demonstrated low complication rate, including infections, thrombosis and bleeding $[2,3]$. However, its use in human abdominal aorta graft replacement has not been used. The objective of this article is to report an abdominal aortic graft infection successfully treated by a bovine pericardial tubular graft.

\section{CASEREPORT}

A 51 year old male was admitted to the hospital with shock due to diabetic ketoacidosis. He had history of alcohol abuse, hypertension, tabacoo use and diabetes mellitus type 2. Four years before admission he had undergone an aortobifemoral bypass for an enlarging 5.5 cm abdominal aortic aneurysm (AAA).

Correspondence address:

Eduardo Dulbecco MD. 1746 Belgrano Av., (C1093AAS), Buenos Aires, Argentina.

E-mail: edulbecco@ffavaloro.org 
On physical examination he had fever, pyodermitis of the right deltoid and left calf area with pain associated in the right shoulder. He also complained of pain of the left arm and leg. Magnetic resonance imaging (MRI) scans of the clinically weak thigh muscles showed high signal on T2 weighted images, suggesting muscle inflammation of the right shoulder and left calf. Arthrocentesis of the right shoulder and blood cultures yielded growth with Streptococcus Agalactiae. Antibiotic treatment with vancomycin intravenously was commenced.

Diagnosis of septic arthritis of multiple joints was done. Due to a suspected infection of the aortobifemoral graft as source of emboli, a CT scan was performed and it showed two fluid collections; the first located around the proximal part of aortic graft and the second around the left leg of the bifurcated graft (Figure 1). CT-guided percutaneous pigtail tube placement and collection drainage was performed.

Exploratory left lumbotomy was done and we certified the communication between the collection and the aortic and left leg limb of the aortobifemoral graft. Culture of percutaneous and surgical samples yielded growth with Stenotrophomona Maltophilia, that microorganism was interpreted as probable contaminant, but it was treated just in case because of high risk of an undertreated prosthetic graft infection. Antibiotic treatment shifted to amoxicillinclavulanic acid, levofloxacin and sulfamethoxazole/ trimethoprim intravenously due to sensibility of both microorganisms.

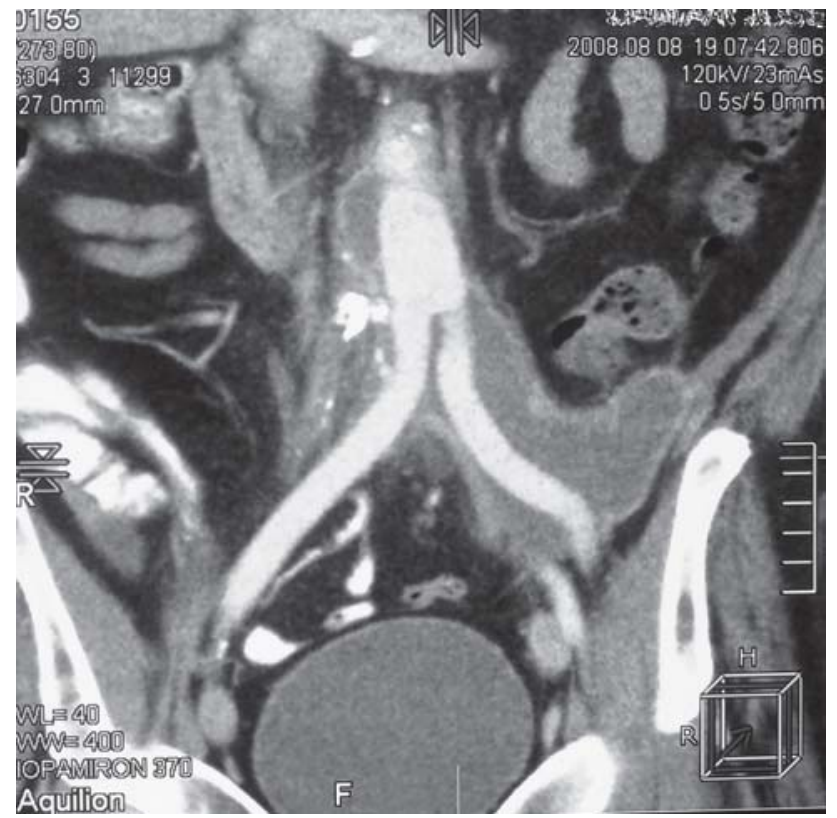

Fig.1 - Preoperative CT scan shows two fluid collections; the first located around the proximal part of aortic graft and the second around the left leg of the bifurcated graft
We decided to do in situ bypass with biological material. In our homograft bank we did not have an aorto-iliac- femoral homograft with enough length to do correct reconstruction, so we request five straight corrugated bovine pericardial tubular graft (Braile Biomedica ${ }^{\mathrm{TM}}$, Sao Paulo, Brazil), one of 21 by $100 \mathrm{~mm}$ and four of 11 by $100 \mathrm{~mm}$ in order to do in situ bypass with biological graft. Patient gave informed consent and was advised of pro and cons of the procedure. Until surgery, patient did well without fever and good glycemic controls. Follow-up CT scan did not show any collection. Patient was followed as out patient with IV antibiotics.

We did median laparotomy and full graft exposure. We found periprosthetic fibrin deposits, with tissue inflammation, without gross purulent material. We measured the length of the aortobifemoral graft in order to make a new bovine pericardial aortobifemoral graft. We constructed a 21 by $11 \mathrm{~mm}$ by $300 \mathrm{~mm}$ length bifurcated tubular graft. For that, we placed a horizontal mattress stitch with Coated, Braided Polyester Sutures (Ticron ${ }^{\mathrm{TM}}$ ) 2/0 stitch in the middle of the 21 by $100 \mathrm{~mm}$ pericardial graft to make two sides (Figure 2), and to each $10,5 \mathrm{~mm}$ orifice we sutured end to end a 11 by $100 \mathrm{~mm}$ pericardial graft and to each limb we added another 11 by $100 \mathrm{~mm}$ graft to reach a new bifurcated 21 by 11 by $300 \mathrm{~mm}$ bovine pericardial graft (Figure 3 ). We did complete removal of the infected aortobifemoral graft and in situ aortobifemoral reconstruction with the constructed bifurcated corrugated bovine pericardial tubular graft (Figure 4).

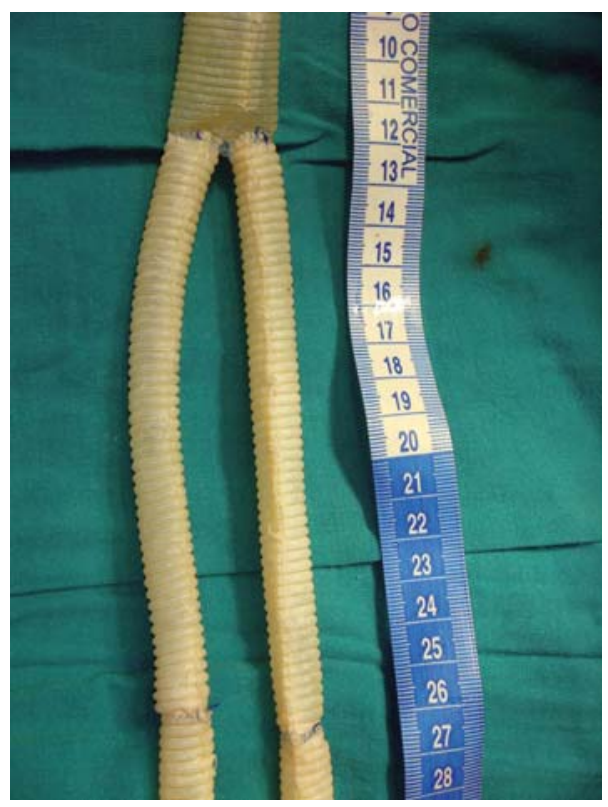

Fig. 2 - Horizontal mattress stitch in the middle of the main body corrugated bovine pericardial tubular graft to make two sides. To each orifice we sutured end to end two limbs 


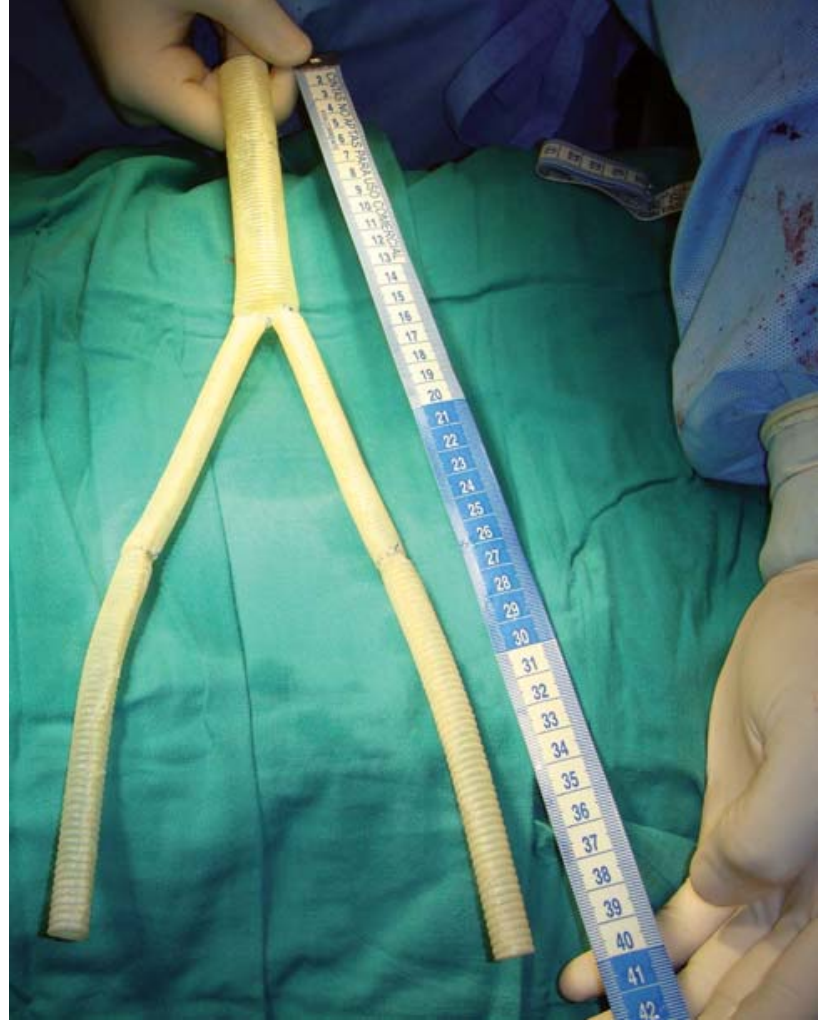

Fig. 3 - Complete constructed bifurcated 21 by 11 by $300 \mathrm{~mm}$ corrugated bovine pericardial tubular graft

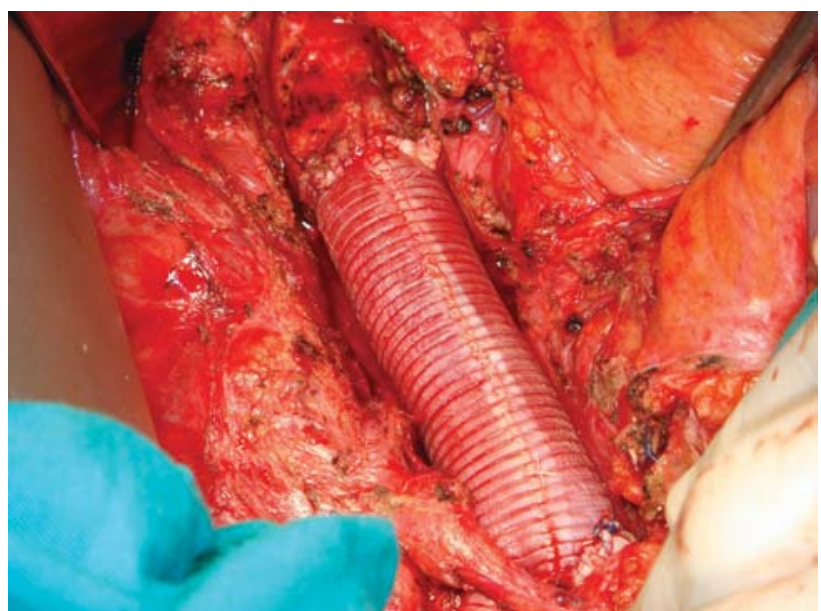

Fig. 4 - In situ aortobifemoral reconstruction with the constructed bifurcated corrugated bovine pericardial tubular graft

Patient recovery was uneventfully and was discharged on postoperative day 5 with oral antibiotics for 6 months. Control CT scan four months after surgery did not reveal any collection or complication (Figure 5).

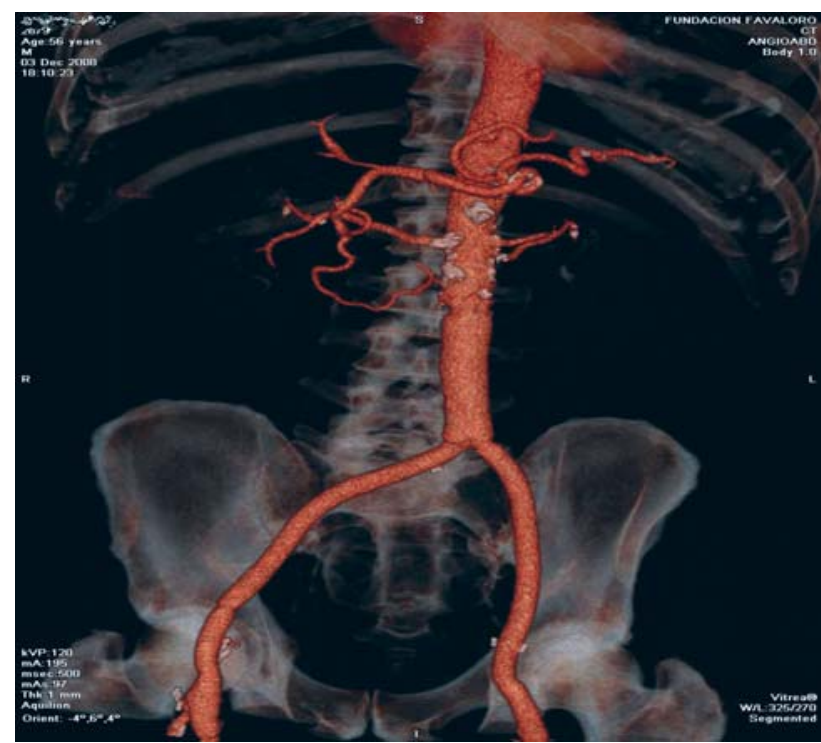

Fig. 5 - Postoperative control CT scan with in situ aortobifemoral reconstruction

\section{DISCUSSION}

Infected aortic prosthetic graft material remains one of the most serious complications of aortic surgery and presents significant treatment challenges [4]. The most widely accepted procedure for arterial reconstruction is extra-anatomic bypass grafting in a sterile field with either immediate or staged complete excision of infected prosthetic material. But long-term patency of these grafts is less than optimal, for axillofemoral bypasses, five-year patency rates of $43 \%$ have been reported. In addition, aortic excision carries the risk of fatal aortic stump blow-out with rates as high as $20 \%$ [4]. Antibiotic-soaked polyester prosthetic graft is an alternate conduit which can be used for in situ aortic reconstruction. Despite the benefits of expedient restoration of in-line flow to the lower extremities, reinfection rates exceed 10\% [5-7]. Autogenous deep femoral and saphenous veins for the creation of a neoaortoiliac system (NAIS) have been used, Beck et al. [8] reported a 5-year primary patency rate of $82 \%$ and and Ali et al. [9] reported a cumulative primary patency at 72 months of $81 \%$ and limb salvage was $89 \%$, with a five-year survival of $52 \%$.

Aortic allograft has been used as a conduit for arterial reconstruction. Studies have demonstrated that cryopreserved allograft replacement is an effective and durable alternative for the treatment of aortic prosthetic graft infection, with improved outcomes in comparison with the traditional treatment of graft excision and extra-anatomic bypass grafting. But concerns about their availability, preservation, and risk of later deterioration avoids the widespread use of this alternative [10-14]. 
Use of bovine pericardial tubular graft has been used for the replacement of thoracic aorta [15-17] and experimental studies probe its use for abdominal aorta reconstruction [18]. However, the use of bovine tubular graft has not been reported for aortobifemoral reconstruction in humans. This report provides an alternative for the surgeon for aorto iliac and femoral reconstruction with biological material for the treatment of aortic graft infection, but long term follow-up will be necessary to confirm its safety.

\section{REFERENCES}

1. Brown KE, Heyer K, Rodriguez H, Eskandari MK, Pearce WH, Morasch MD. Arterial reconstruction with cryopreserved human allografts in the setting of infection: a single-center experience with midterm follow-up. J Vasc Surg. 2009;49(3):660-6.

2. Malashenkov AI, Rusanov NI, Muratov RM, Movsesian RA, Fursov BA, Bykova VA, et al. Eight years clinical experience with the replacement of the ascending aorta using composite xenopericardial conduit. Eur J Cardiothorac Surg. 2000;18(2):168-73.

3. Malashenkov A, Rusanov N, Rychin S, Movsesyan R, Bockeria L. Is it justified to use xenopericardial conduit in the surgery of ascending aortic aneurysms (16.year experience)? Interact CardioVasc Thorac Surg. 2007;6:S1-S172.

4. O’Hara PJ, Hertzer NR, Beven EG, Krajewski LP. Surgical management of infected abdominal aortic grafts: review of a 25-year experience. J Vasc Surg. 1986;3(5):725-31.

5. Oderich GS, Bower TC, Cherry KJ Jr, Panneton JM, Sullivan TM, Noel AA, et al. Evolution from axillofemoral to in situ prosthetic reconstruction for the treatment of aortic graft infections at a single center. J Vasc Surg. 2006;43(6):1166-74.

6. Young RM, Cherry KJ Jr, Davis PM, Gloviczki P, Bower TC, Panneton JM, et al. The results of in situ prosthetic replacement for infected aortic grafts. Am J Surg. 1999;178(2):136-40.

7. Bandyk DF, Novotney ML, Back MR, Johnson BL, Schmacht DC. Expanded application of in situ replacement for prosthetic graft infection. J Vasc Surg. 2001;34(3):411-20.
8. Beck AW, Murphy EH, Hocking JA, Timaran CH, Arko FR, Clagett GP. Aortic reconstruction with femoral-popliteal vein: graft stenosis incidence, risk and reintervention. J Vasc Surg. 2008;47(1):36-44.

9. Ali AT, Modrall JG, Hocking J, Valentine RJ, Spencer H, Eidt $\mathrm{JF}$, et al. Long-term results of the treatment of aortic graft infection by in situ replacement with femoral popliteal vein grafts. J Vasc Surg. 2009;50(1):30-9.

10. Bahnini A, Ruotolo C, Koskas F, Kieffer E. In situ fresh allograft replacement of an infected aortic prosthetic graft: eighteen months' follow-up. J Vasc Surg. 1991;14(1):98-102.

11. Kieffer E, Gomes D, Chiche L, Fleron MH, Koskas F, Bahnini A. Allograft replacement for infrarenal aortic graft infection: early and late results in 179 patients. J Vasc Surg. 2004;39(5):1009-17.

12. Teebken OE, Pichlmaier MA, Brand S, Haverich A. Cryopreserved arterial allografts for in situ reconstruction of infected arterial vessels. Eur J Vasc Endovasc Surg. 2004;27(6):597-602.

13. Vogt PR, Turina MI. Management of infected aortic grafts: development of less invasive surgery using cryopreserved homografts. Ann Thorac Surg. 1999;67(6):1986-98.

14. Vogt PR, Brunner-LaRocca HP, Lachat M, Ruef C, Turina MI. Technical details with the use of cryopreserved arterial allografts for aortic infection: influence on early and midterm mortality. J Vasc Surg. 2002;35(1):80-6.

15. Braile DM, Buffolo E, Leal JCF, Godoy MF, Palma JH, Soares MJF, et al. Proteção cerebral na abordagem cirúrgica do arco aórtico. Rev Soc Cardiol Estado de São Paulo. 1994;4(5):483-92.

16. Croti UA, Braile DM, Moscardi AD, Godoy MF. Cavopulmonar total extracardíaco com tubo de pericárdio bovino corrugado sem auxílio de circulação extracorpórea. Rev Bras Cir Cardiovasc. 2005;20(3):346-7.

17. Silveira LM, Petrucci Jr O, Oliveira PPM, Vieira RW, Braile DM. Aortic reconstruction with bovine pericardial grafts. Rev Bras Cir Cardiovasc. 2003;18(1):9-14.

18. Zhang BG, Chen XF. Experimental studies on arterial reconstruction with bovine pericardial tube. Acta Acad Med Wuhan. 1982;2(2):108-13. 